\title{
Carbons, Ionic Liquids, and Quinones for Electrochemical Capacitors
}

\author{
Raül Díaz-Delgado ${ }^{*}$ and Andrew P. Doherty ${ }^{2}$ \\ ${ }^{1}$ Freelance, Barcelona, Spain (previously affiliated with Electrochemical Processes Unit, IMDEA Energy Institute, Móstoles, \\ Spain), '2 School of Chemistry and Chemical Engineering, Queens' University Belfast, Belfast, UK
}

Carbons are the main electrode materials used in electrochemical capacitors, which are electrochemical energy storage devices with high power densities and long cycling lifetimes. However, increasing their energy density will improve their potential for commercial implementation. In this regard, the use of high surface area carbons and high voltage electrolytes are well-known strategies to increase the attainable energy density, and lately ionic liquids (ILS) have been explored as promising alternatives to current stateof-the-art acetonitrile-based electrolytes. Also, in terms of safety and sustainability, ILs are attractive electrolyte materials for electrochemical capacitors. In addition, it has been shown that the matching of the carbon pore size with the electrolyte ion size further increases the attainable electric double layer (EDL) capacitance and energy density. The use of pseudocapacitive reactions can significantly increase the attainable energy density, and quinonic-based materials offer a potentially sustainable and cost-effective research avenue for both the electrode and the electrolyte. This perspective will provide

OPEN ACCESS

Edited by:

Ángel Berenguer-Murcia, Universidad de Alicante, Spain

Reviewed by: Soshi Shiraishi, Gunma University, Japan Hirotomo Nishihara,

Tohoku University, Japan

*Correspondence: Raül Díaz-Delgado rauldia@gmail.com

Specialty section:

This article was submitted to Carbon-Based Materials,

a section of the journal

Frontiers in Materials

Received: 21 November 2015 Accepted: 02 April 2016

Published: 19 April 2016

Citation:

Díaz-Delgado $R$ and Doherty AP (2016) Carbons, Ionic Liquids, and

Quinones for Electrochemical

Capacitors.

Front. Mater. 3:18.

doi: 10.3389/fmats.2016.00018 an overview of the current state-of-the-art research on electrochemical capacitors based on combinations of carbons, ILs, and quinonic compounds, highlighting performances and challenges and discussing possible future research avenues. In this regard, current interest is mainly focused on strategies, which may ultimately lead to commercially competitive, sustainable high-performance electrochemical capacitors for different applications including those requiring mechanical flexibility and biocompatibility.

Keywords: carbon, ionic liquids, supercapacitors, energy storage, quinones

\section{INTRODUCTION}

Nowadays, there is a great interest in improving our use of energy to make it more affordable and sustainable, thus driving research in grid management and renewable energy implementation and integration. This, together with the increased demands of technological and portable devices, is fostering research on energy storage, which is recognized to be the main challenge for these goals.

While there are many different energy storage technologies, each one characteristic of a certain range of energy and power density range and thus appropriate for certain applications, electrochemical energy storage devices are attractive since they can achieve energy and power ranges not accessible by other technologies and which better suit most of the expected near future demands. Thus, the improvement of electrochemical energy storage devices is one of the most important current challenges.

In this regard, electrochemical capacitors are energy storage devices with high power (up to hundreds of kilowatt per kilogram) and long cycling life (up to several hundred thousand cycles), which require improvements in their currently attainable energy density (around $15 \mathrm{Wh} / \mathrm{kg}$ ) (Winter and Brodd, 2004) to improve their commercialization potential. As a further requisite, the same 
reasons for developing sustainable energy technologies call for the development of sustainable devices for them, and this is critically dependent on the utilization of natural, abundant, and more renewable precursors for materials synthesis (Titirici et al., 2015), coupled with simpler, lower energy processes for material synthesis and device production during the whole life cycle.

\section{STRATEGIES TO INCREASE THE ENERGY DENSITY OF CARBON-BASED ELECTROCHEMICAL CAPACITORS}

According to Eq. (1), the electrical energy storage capacity $(U)$ is a function of the amount of charge accumulated on the electrodes (the capacitance, $C$ ) and the potential difference $(V)$ between the electrodes.

$$
U=\frac{1}{2} \mathrm{CV}^{2}
$$

Electrochemical capacitors can accumulate charge using both double layer and pseudocapacitive mechanisms. Double layer mechanisms are based on electrostatic forces between electrical charges in the electrode and the electrolyte, while pseudocapacitive mechanisms are based on Faradaic redox reactions taking place at the surface of electrodes. The increase of both quantities will hence result in an increased capacitance and thus energy stored, which can be further improved by increasing the operational voltage of the devices. High surface area carbons, quinonic compounds, and ionic liquids (ILs) are considered to be the most promising materials capable of increasing double layer capacitances, pseudocapacitances, and operational voltages, respectively. These topics will thus be the focus of this Perspective.

\section{Increase of the Double Layer Capacitance}

In principle, capacitance increases linearly with surface area, i.e., is an extensive property, therefore high surface area electrode materials are required to maximize energy storage. To satisfy this requirement and also the need for readily available and inexpensive materials, porous high surface area carbons are the most commonly used materials for electrochemical capacitors.

In order to obtain the highest possible double layer capacitances, small-sized pores are preferred since they provide the highest surface areas. Nevertheless, the linear increase of the double layer capacitance with surface area reaches a maximum, which occurs when the pore walls are thinner than the depletion layer and can thus no longer fully compensate the stored charge. In addition, while small-sized pores increase surface area and may greatly enhance capacitance if their size matches the active electrolyte ion size (Chmiola et al., 2006), the transport of ions within them is slow, thus challenging power performances and calling for the presence of larger pores.

Thus, a compromise between energy density and power density can be obtained using hierarchical structures with different pore sizes (Borchardt et al., 2014). In addition, more advanced carbon materials such as carbon nanotubes (CNTs) and graphene also exhibit promising performance due to their outstanding properties arising from their peculiar structures. In this regard, it has been shown that the interfacial capacitance can also depend on, for example, quantum capacitance (Stoller et al., 2011) and that the operational voltage can be expanded, as shown for single walled carbon nanotubes (Izadi-Najafabadi et al., 2010).

Moreover, in the case of carbons doping with heteroatoms, such as N, P, and others (Zhai et al., 2011), increases the free charges, decreases the length of the depletion layer, and allows the increase of the double layer capacitance to hold up to higher surface areas, in addition to result in increased quantum capacitances. Dopants have also been proven to increase the density of states near the Fermi level of carbons such as graphene (Zhang et al., 2012), thus further increasing the attainable capacitances.

\section{Increase of the Pseudocapacitance}

In addition to high surface areas, another way to increase the attainable capacitance is the use of pseudocapacitive reactions. While the capacitance discussed so far is an entirely non-faradaic electrostatic process due to the non-equilibrium charge accumulation at electrode/electrolyte interfaces upon the passage of current or the imposition of an electrochemical potential, which is directly dependent on the amount of charge passed, highly reversible fast faradaic electron transfer reactions such as underpotential electrodeposition or those involving surface redox sites could also store charge via a non-electrostatic mechanism (Conway, 1991). In these systems, the charge-discharge phenomena closely resemble those of classical double layers rather than the potential-dependent faradaic electrochemistry of surface confined species that might be expected. These phenomena were named pseudocapacitance and is essentially a 2-D, or quasi 2-D, surface redox process (Conway, 1991; Simon et al., 2014).

From our perspective of high-surface area carbon materials, it is their rich surface chemistry which naturally gives rise to surface faradaic processes, and, consequently the desirable pseudocapacitance behavior that render carbons very attractive materials for electrochemical capacitor development (Frackowiak and Beguin, 2001). Of the many different types of surface functionalities on native carbons, quinones are the most important due to their simple reversible electrochemistry.

Also, fortuitously, the high reactivity of the carbon surface facilitates the deliberate chemical modification of its surface to enrich it with electroactive hetero-atom functionalities. Of the many possible functionalities, quinone-type groups have received considerable attention, because they are very abundant in nature and can also be easily synthesized, are electrochemically stable, and provide a well-known and convenient fast reversible two-electron redox processes in both aqueous and non-aqueous electrolytes (Patai, 2010) (Figure 1).

Lately, in order to further increase the energy density, the concept of "redox-active electrolytes" has been introduced (Lota and Frackowiak, 2009; Roldan et al., 2011). Along with the idea that electrochemical capacitor power density can be significantly enhanced with the introduction of redox-active electrolytes, the possibility of creating flow capacitors (Hatzell et al., 2015) has emerged.

\section{Increase of the Operational Voltage}

Another way to increase the attainable energy density is to increase the operational voltage of the devices. This has become a major research focus recently with many strategies being proposed 

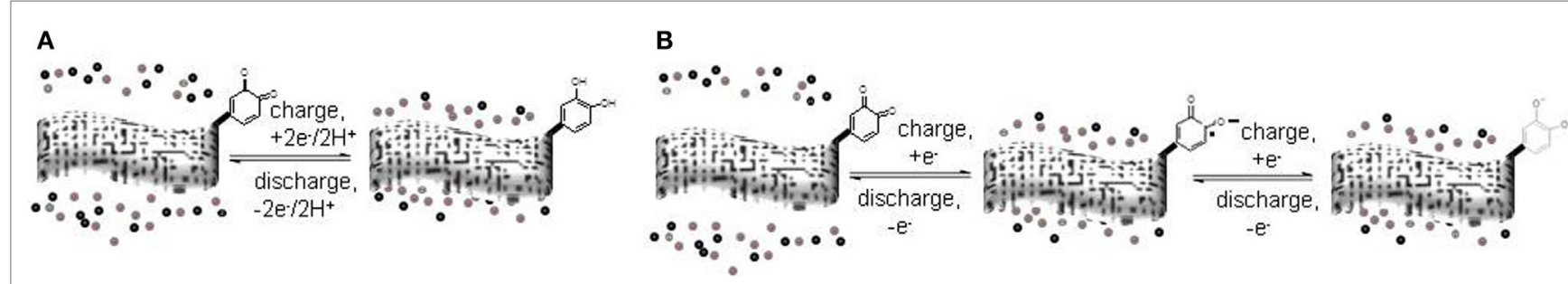

FIGURE 1 | Schematics of the charge and discharge electrochemical reactions of quinone-functionalized carbons in (A) aqueous and (B) nonaqueous electrolytes.

to improve the performance of current acetonitrile-based electrolytes, which can reach up to $2.5-2.7 \mathrm{~V}$ and also have environmental concerns. In this regard, asymmetric (Khomenko et al., 2010) and hybrid (Aravindan et al., 2014) devices have shown their advantage with further progress expected to come from the optimization of high-voltage electrolytes. In this regard, stable ILs, which can reach high voltages and have the potential to be both sustainable and environmentally friendly, have experienced an increased research effort in related devices such as Li-ion batteries (MacFarlane et al., 2016).

Regarding ILs, those receiving most attention are those which are liquid at room temperature, and many current room temperature ionic liquids (RTILs) are air and moisture stable. At their inception (Wilkes and Zaworotko, 1992), it was suggested that RTILs might be important electrolyte materials for capacitor devices and this view has stood the test of time (Hagiwara and Lee, 2007; Arbizzani et al., 2008; Wolff et al., 2015), with early works involving the aromatic imidazolium and pyridinium cations (McEwen et al., 1997; McEwen et al., 1999; Ue and Takeda, 2003).

A small number of key physicochemical properties render RTILs uniquely placed for application in different electrochemical devices: (i) inherently ionically conducting (typically $\mathrm{mS}$ range); (ii) extreme redox robustness [up to $7 \mathrm{~V}$ potential window reported (Sato et al., 2015)]; (iii) non-volatile/non-flammable; (iv) high charge carrier concentration $\left(\gg 1 \mathrm{~mol} \mathrm{~L}^{-1}\right)$; (v) thermal stability; and (vi) liquid state at low temperatures.

Despite the long list of advantageous properties outlined above a few serious adverse properties are well known. First among these is the high viscosity relative to molecular solventbased electrolytes, since few ILs have viscosities of $<30 \mathrm{cP}$ and the common imidazolium and pyrrolidinium ILs have viscosities in the $50-350 \mathrm{cP}$ range. This is more than significantly larger than the viscosities of current state-of-the-art solvents (e.g., $\mathrm{cP}<1$ ). Since ion conductivity is an inverse function of viscosity (Bonhote et al., 1996), the energy storage density is inevitably reduced, in particular for mesoporous or nano-porous materials.

\section{SYNTHESIS OF MATERIALS ON THE WAY TO COMPETITIVE SUSTAINABILITY}

In addition to reaching high-energy density while keeping good power density and long cycling life, electrochemical capacitors are now facing the challenge of sustainability. In this regard, sustainable electrochemical capacitors must include sustainable materials, which have been obtained using sustainable processes. Here, we will give a brief overlook on the preparation procedures, which have been used for the preparation of carbons, quinones, and ILs together with recent issues of improving their sustainability.

\section{Carbons}

Nowadays, most carbon-based materials are obtained from fossilderived precursors and often require harsh or energy intensive synthetic conditions [e.g., electric-arc discharge, chemical vapor deposition (CVD), templating, etc.].

Efforts for synthesizing carbons using renewable biological carbon resources have, until relatively recently, been focused on activated carbons (Ioannidou and Zabaniotou, 2007) because they are those currently used in commercial electrochemical capacitors (Simon and Gogotsi, 2008; Simon et al., 2014). As a further step, naturally abundant and low-cost polysaccharides are among the most promising precursors for the synthesis of porous polymer cryo-, xero-, and aerogels (White et al., 2014), which can be converted to porous carbons. This approach can even valorize otherwise low value polysaccharides, particularly from wastes (White et al., 2010).

More advanced carbon materials such as carbon nanotubes (CNTs) and graphene also exhibit promising performance characteristics but their costs have to be reduced using sustainable synthetic strategies. In this regard, CNTs are typically prepared from a carbon source and metal catalyst particles (Zhang et al., 2011). Thus, for sustainable CNT synthesis, metals and carbon sources from renewable sources are the first step.

Metals can be found in nearly all natural materials and they are usually in the form of small particles, which can be used as catalysts in CNT synthesis. In fact, many minerals such as garnet (beach sand) are effective (Endo et al., 2008), although the diameters of the obtained CNTs have a broad distribution as a consequence of the natural catalyst size. Also, some plant tissues can be used for nanocarbon synthesis (Chen et al., 2009a,b). Regarding biomass-derived carbon sources, those with low $\mathrm{H}$ content such as palm oil (Suriani et al., 2009) are preferred.

With respect to graphene, the reduction of graphene oxide (GO) remains a cost-effective method for large scale graphene production. However, many of the chemicals needed are toxic and harmful, and alternatives such as sugars (Zhu et al., 2010) are proving advantageous. Also, inexpensive carbon sources 
including food, crop waste, insects, and waste with low or negative monetary value can be used without purification to produce high-quality monolayer graphene (Ruan et al., 2011).

Efforts to develop sustainable preparation strategies for these and other advanced carbon-based materials continue, since the possibility to convert even waste carbon into a high-value-added product is very promising.

\section{Quinones and Quinone-Functionalized Carbons}

Many carbons possess naturally occurring surface quinones. However, to increase their capacitance, the type and extent of quinone functionalization can be optimized using different procedures.

Thus, carbons can be "activated" following processes, which increase the surface area of carbons and also functionalize their surfaces via physical or chemical oxidation (Béguin and Frackowiak, 2009). These processes typically result in a wide range of functional groups, which are not all active electrochemically and which may even present incompatible electrochemical behaviors.

Alternative strategies rely on the addition of specific quinonic compounds on the carbon surface to modify the electrode/ electrolyte interface while keeping the inherent properties of the active materials. By far, the most popular strategy is the use of aryl diazonium salts (Chehimi, 2012; Assresahegn et al., 2015). These organic layers can be grafted on a substrate: (i) by electrochemical induction, (ii) photochemically under UV/visible light, (iii) with ultrasound assistance, (iv) by ball-milling, or (v) by using a reducing agent and spontaneously. In particular, spontaneous functionalization is very convenient for mass production, with many patents issued (Belmont et al., 2012).

Diazonium chemistry has also been applied to metals (Bernard et al., 2003; Combellas et al., 2005), metal oxides (Pinson and Podvorica, 2005), and silicon (Henry De Villeneuve et al., 1997), and for electrochemical capacitors, different quinones have been grafted on carbonaceous surfaces (Kalinathan et al., 2008; Pognon et al., 2012; Le Comte et al., 2015). Thus, it is possible to obtain surfaces bearing a wide variety of organic functionalities, which can also influence the wettability and be further modified. In addition, the redox potential of these species should be carefully chosen to provide additional charge at the beginning of discharge of the electrochemical capacitor, when its voltage is high. In this regard, the feasibility of pseudocapacitance in organic electrolytes using quinone species (Song et al., 2009; Nueangnoraj et al., 2015) potentially allows an increase of the operational voltage.

Nevertheless, this method needs further improvements such as the control of layers added and the increase of the extent of coverage (Doppelt et al., 2007). Hence, other strategies based on physical (Isikli and Díaz, 2012), chemical (Isikli et al., 2014), and electrochemical (Le Comte et al., 2014) methods are being pursued. Since pseudocapacitive reactions may also increase capacitances in confined spaces (Isikli et al., 2014) and in "redoxactive" and flowable electrolytes, their optimization is of utmost interest.
Sustainability issues in this field have, as yet, not been adequately addressed. However, since quinonic compounds are widely distributed in nature, renewable natural materials are likely to contribute significantly to their sustainability. This is proven by the interest on the use of quinonic compounds as potentially sustainable materials in other electrochemical energy storage devices such as Li-ion (Chen et al., 2009a,b) or redox flow (Huskinson et al., 2014; Lin et al., 2015) batteries.

\section{Ionic Liquids}

The high viscosity, and low ionic conductivity, of ILs is their main drawback as electrochemical capacitor electrolytes, and at least for relatively low molecular-weight cations, the viscosities are controlled by the anion (Galinski et al., 2006). This, together with the inverse relation between capacitance and ion size (Nanjundiah et al., 1997; McEwen et al., 1999) and the high improvement of EDL capacitance when the electrolyte ion size matches the pore size of the electrode materials (Chmiola et al., 2006) highlights the importance of the right choice of ions to optimize the performance of IL electrolytes in electrochemical capacitors.

In this regard, the precise size of the ions in ILs is a clear advantage compared to the poorly defined ion solvation shells present in common solvents, since it facilitates the design and synthesis of ILs. In this regard, while according to the abovementioned criteria, the choice of anions is in principle restricted to non-coordinating anions (Figure 2) such as bistriflate $\left(\mathrm{NTf}_{2}\right)$, tetrafluoroborate $\left(\mathrm{BF}_{4}\right)$, and dicyanamide (DCA), the different heterogeneous bulk and interfacial electrode/electrolyte structures of ILs compared to common electrolytes may provide other research avenues (Galinski et al., 2006; Hayes et al., 2011), which can also include pseudocapacitive reactions, also possible in ILs (Rochefort and Pont, 2006).

Thus, ILs hold great promise and offer many research avenues as electrochemical capacitor electrolytes. From our perspective, one of these avenues is the study of their sustainability including all their production and recycling processes. In this regard, the synthesis of anions and cations can benefit from current efforts on green chemistry, while the synthesis of ILs should overcome current concerns on their expected purity to lower their cost. Nonetheless, the cost will be less pressing in high-added value

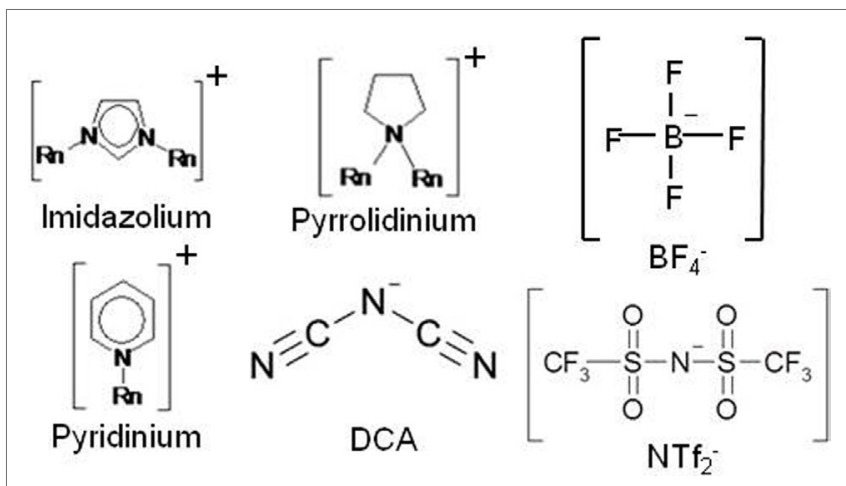

FIGURE 2 | Structure of some common cations and anions in ILs. 
devices such as portable devices, for which gelled and polymeric ILs provide clear advantages.

\section{SOME EFFORTS FOR SUSTAINABLE COMPETITIVE DEVICES}

In the case of electrochemical capacitors, one of the main foreseen applications is in portable individual devices, such as those to be integrated in smart textiles (Jost et al., 2014). These devices pose additional requirements for electrochemical capacitors, i.e., flexibility and even biocompatibility, which must be further addressed by the components. In this regard, carbon materials are well suited for bendable electrodes for which processes such as inkjet printing may provide further advantages in cost and sustainability, and the functionalization of carbons with surface quinonic groups is not an issue in this context.

Compared to liquid electrolytes, polymer gel electrolytes, where a conventional electrolyte solution is entrapped within the 3-D open network of a polymer gel (Sung et al., 1998; Agrawal and Pandey, 2008; Pandey and Hashmi, 2013a,b), are attractive in flexible and portable devices for a number of reasons including mechanical stability, leakage prevention, high ionic conductivity, high interfacial stability, and ease of fabrication.

While initial reports of ionic liquid gel polymer electrolytes (ILGPEs) had limited performances due to their high viscosities (Fuller et al., 1998), recently a ILGPE composed of

\section{REFERENCES}

Agrawal, R. C., and Pandey, G. P. (2008). Solid polymer electrolytes: materials designing and all-solid-state battery applications: an overview. J. Phys. D Appl. Phys. 41, 223001. doi:10.1088/0022-3727/41/22/223001

Aravindan, V., Gnanaraj, J., Lee, Y. S., and Madhavi, S. (2014). Insertion-type electrodes for non-aqueous Li-ion capacitors. Chem. Rev. 114, 11619-11635. doi:10.1021/cr5000915

Arbizzani, C., Biso, M., Cericola, D., Lazzari, M., Soavi, F., and Mastragostino, M. (2008). Safe, high-energy supercapacitors based on solvent-free ionic liquid electrolytes. J. Power Sources 185, 1575-1579. doi:10.1016/j.jpowsour.2008.09.016

Assresahegn, B. D., Brousse, T., and Bélanger, D. (2015). Advances on the use of diazonium chemistry for functionalization of materials used in energy storage systems. Carbon N. Y. 92, 362-381. doi:10.1016/j.carbon.2015.05.030

Béguin, F., and Frackowiak, E. (2009). Carbons for Electrochemical Energy Storage and Conversion Systems. New York: CRC Press.

Belmont, J.A., Bureau, C., Chehimi, M. M., Gam-Derouich, S., and Pinson, J. (2012). Aryl Diazonium Salts. Weinheim: VCH Verlag GmbH\&Co. KGaA.

Bernard, M. C., Chaussé, A., Cabet-Deliry, E., Chehimi, M. M., Pinson, J., Podvorica, F., et al. (2003). Organic layers bonded to industrial, coinage, and noble metals through electrochemical reduction of aryldiazonium salts. Chem. Mater. 15, 3450-3462. doi:10.1021/cm034167d

Bonhote, P., Dias, A. P., Papageorgiou, N., Kalyanasundaram, K., and Gratzel, M. (1996). Hydrophobic, highly conducting ambient-temperature molten salts. Inorg. Chem. 35, 1168-1178. doi:10.1021/ic951325x

Borchardt, L., Oschatz, M., and Kaskel, S. (2014). Tailoring porosity in carbon materials for supercapacitor applications. Mater. Horiz. 1, 157-168. doi:10.1039/ C3MH00112A

Chehimi, M. M. (2012). Aryl Diazonium Salts: New Coupling Agents and Surface Science. Weinheim: Wiley-VCH.

Chen, H., Armand, M., Courty, M., Jiang, M., Grey, C. P., Dolhem, F., et al. (2009a). Lithium salt of tetrahydroxybenzoquinone: toward the evelopment of a sustainable li-ion battery. J. Am. Chem. Soc. 131, 8984-8988. doi:10.1021/ja9024897

Chen, X. W., Timpe, O., Hamid, S. B. A., Schlogl, R., and Su, D. S. (2009b). Direct synthesis of carbon nanofibers on modified biomass-derived activated carbon. Carbon N. Y. 47, 340-343. doi:10.1016/j.carbon.2008.11.001 1-ethyl-3-methylimidazolium tetracianoborate ([Emim][TCB]) and PVdFHFP, in combination with multi-walled carbon nanotube electrodes exhibited essentially equivalent characteristics as devices constructed from pure ([Emim][TCB]) (Pandey and Hashmi, 2013a,b). While ILGPEs have exhibited high working voltages of $4.4 \mathrm{~V}$ (Pandey and Hashmi, 2013a,b), further improvements and advances in this field, such as the in situ polymerization of "IL monomers" (Song et al., 2015) are being steadily reported with the ultimate goal to achieve sustainable competitive materials. In this regard, solid electrolytes are another research avenue, and recently a solid polymer electrolyte electrochemical capacitor incorporating an IL ( $N, N$-diethyl- $N$-(2-methoxy-ethyl)- $N$-methylammonium bis(trifluoromethyl sulfonyl)imide [DEME] $\left[\mathrm{NTf}_{2}\right]$ ) reached a stable working potential of $7.5 \mathrm{~V}$ (Sato et al., 2015).

Thus, while the combination of carbons, ILs, and quinones hold a great promise for the development of sustainable competitive electrochemical capacitors, at least for applications such as those mentioned in this perspective, with all these components at hand sustainable device production processes should also be taken into account, and many research efforts are currently underway to overcome these challenges.

\section{AUTHOR CONTRIBUTIONS}

Both authors contributed to the development of the manuscript and wrote it.

Chmiola, J., Yushin, G., Gogotsi, Y., Portet, C., Simon, P., and Taberna, P. L. (2006). Anomalous increase in carbon capacitance at pore sizes less than 1 nanometer. Science 313, 1760-1763. doi:10.1126/science.1132195

Combellas, C., Delamar, M., Kanoufi, F., Pinson, J., and Povorica, F. I. (2005). Spontaneous grafting of iron surfaces by reduction of aryldiazonium salts in acidic or neutral aqueous solution. Application to the protection of iron against corrosion. Chem. Mater. 17, 3968-3975. doi:10.1021/cm050339q

Conway, B. E. (1991). Transition from "supercapacitor" to "battery" behavior in electrochemical energy storage. J. Electrochem. Soc. 138, 1539-1548. doi:10.114 9/1.208582910.1149/1.2085829

Doppelt, P., Hallais, G., Pinson, J., Podvorica, F., and Verneyre, S. (2007). Surface modification of conducting substrates. Existence of azo bondds in the structure of organic layers obtained from diazonium salts. Chem. Mater. 19, 4570-4575. doi:10.1021/cm0700551

Endo, M., Takeuchi, K., Kim, Y. A., Park, K. C., Ichiki, T., Hayashi, T., et al. (2008). Simple synthesis of multiwalled carbon nanotubes from natural resources. ChemSusChem 1, 820-822. doi:10.1002/cssc.200800150

Frackowiak, E., and Beguin, F. (2001). Carbon materials for the electrochemical storage of energy in capacitors. Carbon N. Y. 39, 937-950. doi:10.1016/ S0008-6223(00)00183-4

Fuller, J., Breda, A. C., and Carlin, R. T. (1998). Ionic liquid-polymer gel electrolytes from hydrophilic and hydrophobic ionic liquids. J. Electroanal. Chem. 459, 29-34. doi:10.1016/S0022-0728(98)00285-X

Galinski, M., Lewandowsk, L., and Stepniak, I. (2006). Ionic liquids as electrolytes. Electrochim. Acta 51, 5567-5580. doi:10.1016/j.electacta.2006.03.016

Hagiwara, R., and Lee, J. S. (2007). Ionic liquids for electrochemical devices. Electrochemistry 75, 23-34. doi:10.5796/electrochemistry.75.23

Hatzell, K. B., Boota, M., and Gogotsi, Y. (2015). Materials for suspension (semi-solid) electrodes for energy and water technologies. Chem. Soc. Rev. 44, 8664-8687. doi:10.1039/c5cs00279f

Hayes, R., Imberti, S., Warr, G. G., and Atkin, R. (2011). Pronounced sponge-like nanostructure in propylammonium nitrate. Phys. Chem. Chem. Phys. 13, 13544-13551. doi:10.1039/C1CP21080G

Henry De Villeneuve, C., Pinson, J., Bernard, M. C., and Allongue, P. (1997). Electrochemical formation of close-packed phenyl layers on $\mathrm{Si}(111)$. J. Phys. Chem. B 101, 2415-2420. doi:10.1021/jp962581d 
Huskinson, B., Marshak, M., Suh, C., Er, S., Gerhardt, M., Galvin, C., et al. (2014). A metal-free organic-inorganic aqueous flow battery. Nature 505, 195-198. doi:10.1038/nature12909

Ioannidou, O., and Zabaniotou, A. (2007). Agricultural residues as precursors for activated carbon production-A review. Renew. Sust. Energy Rev. 11, 1966-2005. doi:10.1016/j.rser.2006.03.013

Isikli, S., and Díaz, R. (2012). Substrate-dependent performance of supercapacitors based on an organic redox couple impregnated on carbon. J. Power Sources 206, 53-58. doi:10.1016/j.jpowsour.2012.01.088

Isikli, S., Lecea, M., Ribagorda, M., Carreno, M. C., and Diaz, R. (2014). Influence of quinone grafting via Friedel-Crafts reaction on carbon porous structure and supercapacitor performance. Carbon N. Y. 66, 654-661. doi:10.1016/j. carbon.2013.09.062

Izadi-Najafabadi, A., Yasuda, S., Kobashi, K., Yamada, T., Futaba, D. N., Hatori, H., et al. (2010). Extracting the full potential of single-walled carbon nanotubes as durable supercapacitor electrodes operable at $4 \mathrm{~V}$ with high power and energy density. Adv. Mater. 22, E235-E241. doi:10.1002/adma.200904349

Jost, K., Dion, G., and Gogotsi, Y. (2014). Textile energy storage in perspective. J. Mater. Chem. A 2, 10776-10787. doi:10.1039/C4TA00203B

Kalinathan, K., DesRoches, D. P., Liu, X., and Pickup, P. G. (2008). Anthraquinone modified carbon fabric supercapacitors with improved energy and power densities. J. Power Sources 181, 182-185. doi:10.1016/j.jpowsour.2008.03.032

Khomenko, V., Raymundo-Piñero, E., and Béguin, F. (2010). A new type of high energy asymmetric capacitor with nanoporous carbon electrodes in aqueous electrolyte. J. Power Sources 195, 4234-4241. doi:10.1016/j.jpowsour. 2010.01.006

Le Comte, A., Brousse, T., and Bélanger, D. (2014). Simpler and greener grafting for improving the stability of anthraquinone-modified carbon electrode in alkaline media. Electrochim. Acta 137, 447-453. doi:10.1016/j.electacta. 2014.05.155

Le Comte, A., Chhin, D., Gagnon, A., Retoux, R., Brousse, T., and Bélanger, D. (2015). Spontaneous grafting of 9,10-phenanthrenequinone on porous carbon as an active electrode material in an electrochemical capacitor in an alkaline electrolyte. J. Mater. Chem. A 3, 6146-6156. doi:10.1039/C4TA05536E

Lin, K., Chen, Q., Gerhardt, M. R., Tong, L., Kim, S. B., Eisenach, L., et al. (2015). Alkaline quinone flow battery. Science 349, 1529-1532. doi:10.1126/science. aab3033

Lota, G., and Frackowiak, E. (2009). Striking capacitance of carbon/iodide interface. Electrochem. Commun. 11, 87-90. doi:10.1016/j.elecom.2008.10.026

MacFarlane, D. R., Forsyth, M., Howlett, P. C., Kar, M., Passerini, S., Pringle, J. M., et al. (2016). Ionic liquids and their solid-state analogues as materials for energy generation and storage. Nat. Rev. Mater. 1, 15005. doi:10.1038/ natrevmats. 2015.5

McEwen, A. B., McDevitt, S. F., and Koch, V. R. (1997). Nonaqueous electrolytes for electrochemical capacitors: imidazolium cations and inorganic fluorides with organic carbonates. J. Electrochem. Soc. 144, L84-L86. doi:10.1149/ 1.1837561

McEwen, A. B., Ngo, H. L., LeCompt, K., and Goldman, J. L. (1999). Electrochmical properties of imidazolium salt electrolytes for electrochemical capacitor applications. J. Electrochem. Soc. 146, 1687-1695. doi:10.1149/1.1391827

Nanjundiah, C., McDevitt, S. F., and Koch, V. R. (1997). Differential capacitance measurements in solvent-free ionic liquids at $\mathrm{Hg}$ and Cinterfaces. J. Electrochem. Soc. 144, 3392-3397. doi:10.1149/1.1838024

Nueangnoraj, K., Nishihara, H., Ishii, T., Yamamoto, N., Itoi, H., Berenguer, R., et al. (2015). Pseudocapacitance of zeolite-templated carbon in organic electrolytes. Energy Storage Mater. 1, 35-41. doi:10.1016/j.ensm.2015.08.003

Pandey, G. P., and Hashmi, S. A. (2013a). Performance of solid-state supercapacitors with ionic liquid 1-ethyl-3-methylimidazolium tris(pentafluoroethyl) trifluorophosphate based gel polymer electrolyte and modified MWCNT electrodes. Electrochim. Acta 105, 333-341. doi:10.1016/j.electacta. 2013.05.018

Pandey, G. P., and Hashmi, S. A. (2013b). Ionic liquid 1-ethyl-3-methylimidazolium tetracyanoborate-based gel polymer electrolyte for electrochemical capacitors. J. Mater. Chem. A 1, 3372-3378. doi:10.1039/C2TA01347A

Patai, S. (2010). Chemistry of the Quinonoids Compounds. Weinheim: Wiley.

Pinson, J., and Podvorica, F. (2005). Attachment of organic layers to conductive or semiconductive surfaces by reduction of diazonium salts. Chem. Soc. Rev. 34, 429-439. doi:10.1039/B406228K
Pognon, G., Cougnon, C., Mayilukila,D., and Bélanger,D.(2012).Cathecol-modified activated carbon prepared by the diazonium chemistry for application as active electrode material in electrochemical capacitor. ACS Appl. Mater. Interfaces 4, 3788-3796. doi:10.1021/am301284n

Rochefort, D., and Pont, A. L. (2006). Pseudocapacitive behaviour of RuO2 in a proton exchange ionic liquid. Electrochem. Commun. 8, 1539-1543. doi:10.1016/j. elecom.2006.06.032

Roldan, S., Blanco, C., Granda, M., Menendez, R., and Santamaria, R. (2011). Towards a further generation of high-energy carbon-based capacitors by using redox-active electrolytes. Angew. Chem. Int. Ed. 50, 1699-1701. doi:10.1002/ anie. 201006811

Ruan, G. D., Sun, Z. Z., Peng, Z. W., and Tour, J. M. (2011). Growth of graphene from food, insects, and waste. ACS Nano 5, 7601-7607. doi:10.1021/ nn202625c

Sato, T., Murukane, S., Morinaga, T., Kamijo, T., Arafune, H., and Tsujii, Y. (2015). High voltage electric double layer capacitor using a novel solid-state polymer electrolyte. J. Power Sources 295, 108-116. doi:10.1016/j.jpowsour. 2015.06.116

Simon, P., and Gogotsi, Y. (2008). Materials for electrochemical capacitors. Nat. Mater. 7, 845-854. doi:10.1038/nmat2297

Simon, P., Gogotsi, Y., and Dunn, B. (2014). Materials science. Where do batteries end and supercapacitors begin? Science 343, 1210-1211. doi:10.1126/ science. 1249625

Song, P., Gao, M., Su, Y., Zhao, J., and Zou, G. (2015). In situ thermal polymerization of an ionic liquid monomer for quasi-solid-state dye-sensitized solar cells. J. Appl. Polym. Sci. 132, 42802. doi:10.1002/app.42802

Song, Z., Zhan, H., and Zhou, Y. (2009). Anthraquinone based polymer as high performance cathode material for rechargeable lithium batteries. Chem. Commun. 448-450. doi:10.1039/B814515F

Stoller, M. D., Magnuson, C. W., Zhu, Y., Murali, S., Suk, J. W., Piner, R., et al. (2011). Interfacial capacitance of single layer graphene. Energy Environ. Sci. 4, 4685-4689. doi:10.1039/C1EE02322E

Sung, H. Y., Wang, Y. Y., and Wan, C. C. (1998). Preparation and characterization of poly(vinyl chloride-co-vinyl acetate)-based gel electrolytes for Li-ion batteries. J. Electrochem. Soc. 145, 1207-1211. doi:10.1149/1.1838440

Suriani, A. B., Azira, A. A., Nik, S. F., Nor, R. M., and Rusop, M. (2009). Synthesis of vertically aligned carbon nanotubes using natural palm oil as carbon precursor. Mater. Lett. 63, 2704-2706. doi:10.1016/j.matlet.2009.09.048

Titirici, M. M., White, R. J., Brun, N., Budarin, V. L., Su, D. S., del Monte, F., et al. (2015). Sustainable carbon materials. Chem. Soc. Rev. 44, 250-290. doi:10.1039/ $\mathrm{C} 4 \mathrm{CS} 00232 \mathrm{~F}$

Ue, M., and Takeda, M. (2003). Application of low-viscosity ionic liquid to the electrolyte of double-layer capacitors. J. Electrochem. Soc. 150, A499-A502. doi:10.1149/1.1559069

White, R. J., Brun, N., Budarin, V. L., Clark, J. H., and Titirici, M. M. (2014). Always look on the "light" side of life: sustainable carbon aerogels. ChemSusChem 7, 670-689. doi:10.1002/cssc.201300961

White, R. J., Budarin, V. L., and Clark, J. H. (2010). Pectin-derived porous materials. Chemistry 16, 1326-1335. doi:10.1002/chem.200901879

Wilkes, J. S., and Zaworotko, M. J. (1992). Air and water stable 1-ethyl-3-methylimidazolium based ionic liquids. Chem. Commun. 13, 965-967. doi:10.1039/ C39920000965

Winter, M., and Brodd, R. J. (2004). What are batteries, fuel cells, and supercapacitors? Chem. Rev. 104, 4245-4269. doi:10.1021/cr020730k

Wolff, C., Jeong, S., Paillard, E., Balducci, A., and Passerini, S. (2015). High power solvent-free electrochemical double layer capacitors based on pyrrolidinium dicyanamide ionic liquids. J. Power Sources 293, 65-70. doi:10.1016/j. jpowsour.2015.05.065

Zhai, Y., Dou, Y., Zhao, D., Fulvio, P. F., Mayes, R. T., and Dai, S. (2011). Carbon materials for chemical capacitive energy storage. Adv. Mater. 23, 4828-4850. doi:10.1002/adma.201100984

Zhang, L. L., Zhao, X., Ji, H., Stoller, M. D., Lai, L., Murali, S., et al. (2012). Nitrogen doping of graphene and its effect on quantum capacitance, and a new insight on the enhanced capacitance of N-doped carbon. Energy Environ. Sci. 5, 9618-9625. doi:10.1039/C2EE23442D

Zhang, Q., Huang, J. Q., Zhao, M. Q., Qian, W. Z., and Wei, F. (2011). Carbon nanotube mass production: principles and processes. ChemSusChem 4, 864-889. doi:10.1002/cssc. 201100177 
Zhu, C. Z., Guo, S. J., Fang, Y. X., and Dong, S. J. (2010). Reducing sugar: new functional molecules for the green synthesis of graphene nanosheets. ACS Nano 4, 2429-2437. doi:10.1021/nn1002387

Conflict of Interest Statement: The authors declare that the research was conducted in the absence of any commercial or financial relationships that could be construed as a potential conflict of interest.
Copyright (c) 2016 Día-Delgado and Doherty. This is an open-access article distributed under the terms of the Creative Commons Attribution License (CC BY). The use, distribution or reproduction in other forums is permitted, provided the original author(s) or licensor are credited and that the original publication in this journal is cited, in accordance with accepted academic practice. No use, distribution or reproduction is permitted which does not comply with these terms. 